\title{
Physician Payment Disclosure Under Health Care Reform: Will the Sun Shine?
}

\author{
Tim K. Mackey, MAS, and Bryan A. Liang MD, PhD, JD
}

Pharmaceutical marketing has become a mainstay in U.S. health care delivery and traditionally has been directed toward physicians. In an attempt to address potential undue influence of industry and conflicts of interest that arise, states and the recently upheld health care reform act have passed transparency, or "sunshine," laws requiring disclosure of industry payments to physicians. The Centers for Medicare \& Medicaid Services recently announced the final rule for the Sunshine Provisions as part of the reform act. However, the future effectiveness of these provisions are questionable and may be limited given the changing landscape of pharmaceutical marketing away from physician detailing to other forms of promotion. To address this changing paradigm, more proactive policy solutions will be necessary to ensure adequate and ethical regulation of pharmaceutical promotion. ( $\mathrm{J}$ Am Board Fam Med 2013;26: 327-331.)

Keywords: Conflict of Interest, Health Care Reform, Health Policy, Medical Ethics

Pharmaceutical marketing has been an American health care issue from as early as the 1950s, when Senator Estes Kefauver first questioned the relationship between large marketing expenditures and high drug costs. ${ }^{1}$ Since then, the debate regarding drug marketing has continued, along with increased industry spending.

Analysis has shown that, from 1996 to 2005, drug company marketing expenditures more than tripled, from $\$ 11.4$ to $\$ 29.9$ billion. $^{2}$ Concomitantly, prescription drug spending has increased nearly 6-fold, from $\$ 40.3$ billion in 1990 to $\$ 234.1$ billion in 2008, with profits exceeding many other Fortune 500 industries. ${ }^{3}$

A high fraction of these funds traditionally have been spent on direct-to-physician promotion. ${ }^{4}$ As

This article was externally peer reviewed.

Submitted 24 September 2012; revised 4 December 2012; accepted 2 January 2013.

From the Institute of Health Law Studies, California Western School of Law, San Diego (TKM, BAL); the Joint Doctoral Program on Global Health, University of California San Diego/San Diego State University, San Diego (TKM); the San Diego Center for Patient Safety and the Department of Anesthesiology, University of California San

Diego School of Medicine, San Diego (BAL).

Funding: none.

Conflict of interest: none declared.

Corresponding author: Tim K. Mackey, Institute of Health Law Studies, California Western School of Law, 350 Cedar Street, San Diego, CA 92101 (E-mail: tmackey@ucsd.edu). gatekeepers, physicians represent key decision makers in prescription drug use, particularly of brand-name pharmaceuticals. Yet efforts to influence physician prescribing habits are legion, including large-scale pharmaceutical detailing by industry sales representatives, gifts and payments, free meals, payment for travel, no-fee continuing medical education, grants, payment for "consulting services," ghostwriting, and excessive honorariums. $^{4,5}$

These expenditures are costly to the health care system. But conflicts of interest (COIs) at both the individual and institutional levels can have a negative effect beyond higher drug prices. ${ }^{4,5}$ This includes influences on physician that can lead to negative patient implications, including (1) incorrect drug claims and uses; (2) formulary requests for medications with no significant advantage over existing medication; (3) irrational prescribing; (4) fewer prescribed generics; and (5) compromising integrity in clinical decision making that can lead to patient safety issues. ${ }^{5,6}$

In response, the federal government has attempted to improve transparency in physician-industry relationships in the recently upheld health care reform act. Here we assess the potential effect of these provisions on the evolving environment of pharmaceutical marketing. 


\section{State Sunshine Laws}

Before federal efforts, several states enacted "sunshine laws" requiring disclosure of payments to physicians and enacting certain marketing limitations to address physician-industry COIs. ${ }^{7}$ These laws vary widely in restrictions and scope of transparency and have offered only fragmented solutions with limited effectiveness. ${ }^{8,9}$ As an example, 5 states-Minnesota, Vermont, West Virginia, Maine, Massachusetts - and the District of Columbia have adopted physician payment disclosure laws; other states introduced legislation that failed to become law. ${ }^{10}$ However, state laws have been challenged regularly by the pharmaceutical industry and vary based on what amounts and categories are disclosed, the type of entities subject to disclosure, public accessibility to data, exemptions to reporting, and different levels of enforcement. ${ }^{10}$

Other states have moved progressively beyond disclosure, with states such as California requiring adherence to government guidance and industry codes of marketing, public disclosure, the establishment of compliance programs for promotion, and limits on gifts and incentives to medical and health care professionals $(\mathrm{eg}, \leq \$ 100) .{ }^{10}$ Massachusetts has laws that not only require physician to disclose payments but also ban specific forms of gifts and payments given to physicians. ${ }^{10}$ However, because of economic concerns and challenges from businesses, the Massachusetts law recently has been amended to allow forms of free meals and reduce disclosure requirements.

\section{Federal Physician Payment Sunshine Act}

In response to these transparency actions by states and growing concern regarding physician-industry relationships, in 2007, Senators Charles Grassley and Herb Kohl first introduced proposed federal legislation called The Physicians Payment Sunshine Act of 2007, requiring public disclosure of payments to physicians from the industry, but it failed to be enacted. Instead, it would take sweeping health care reform that incorporated the Sunshine Act and the recent US Supreme Court ruling to solidify the legislation into law.

On March 23, 2010, President Barak Obama signed into law the Patient Protection and Affordable Care Act (ACA) with the aim of extending insurance coverage to some 32 million additional Americans through significant health care reform.
The ACA also explicitly includes goals of cost containment through various reform measures. ${ }^{11}$ Made part of this historical reform were the provisions of the Physician Payment Sunshine Act. The goals of the Sunshine Act are to "shed light" on financial ties between industry and physicians, with the aim of dissuading inappropriate COIs that may compromise clinical integrity and patient care and lead to increased costs in health care. ${ }^{12}$

The act includes mandated disclosure by drug and device manufacturers and group purchasing organizations of payments to physicians and teaching hospitals as well as enforcement mechanisms through imposition of penalties for noncompliance. ${ }^{12}$ Disclosure encompasses a number of categories including: entertainment and gifts, food, travel, consulting fees, speaking fees, compensation for services (other than consulting fees), honoraria, certain research-related funding or grants, education or conference funding, physician ownership and investment interests, forms of equity, royalties or licenses, and charitable contributions paid by the industry, which must be reported to the Department of Health and Human Services, which then will make the information public. ${ }^{12}$ Certain forms of payments are exempt (eg, samples, de minimis payments of $<\$ 10$ and $<\$ 100$ in the aggregate [subject to consumer price index adjustments each year], certain educational materials, certain indirect payments, short-term loans, rebates, and discounts). These categories largely mirror statebased payment transparency exemptions and are meant to reduce the burden of reporting for categories not deemed to have a significant effect on physician-industry COIs.

The Sunshine Act represents a milestone in raising awareness and transparency for drug marketing and includes penalties of up to $\$ 1$ million for entities who knowingly fail to report. ${ }^{12}$ If successful, the ACA's Sunshine Act has the potential to have an effect on health care, including potentially lowering costs and increasing rational use of drugs, discouraging inappropriate physician-industry COIs, and promoting ethical marketing practices.

Despite these potential benefits, the act ran into opposition and a delay before the final binding rule recently announced by the Centers of Medicare and Medicaid Services (CMS), largely due to industry challenges. ${ }^{13}$ This included calls to minimize purported unnecessary regulatory and reporting burdens for industry, concerns about the cost of 
compliance, and effect on funding of medical research and CME; a letter issued by certain members of Congress with medical backgrounds voiced such concerns. The final rule of the act, called the National Physician Payment Transparency Program: Open Payments, has delayed required data collection to August 1, 2013, and reporting to March 31, 2014. ${ }^{12}$ Although it retains key elements of the proposed rule, the final rule now exempts the reporting of indirect payments associated with continuing education programs that meet certain accreditation or certification requirements and are not paid directly to a covered recipient. ${ }^{12}$ The final rule also exempts aggregate reporting for certain large-scale events open to the public (ie, conferences), clarifies that residents are excluded, and allows for an additional 15 days for reporting entities to correct and dispute data after the close of the annual review period, including requesting that the data be marked as "disputed" by CMS. ${ }^{12}$

Collectively, these limitations to reporting highlight troubling aspects of the political influence of the industry in challenging public policy and may limit data collection under the Sunshine Act. Indeed, industry trade groups, such as PhRMA and AdvaMed, have attempted to preempt the act by enacting voluntary, nonbinding codes of conduct to address physician-industry relationships that have been largely criticized as ineffective. These developments point to major challenges even before the act's provisions are implemented fully. These are exacerbated by a more sobering reality: the evolving nature of pharmaceutical marketing away from physician promotion.

\section{Limited Impact? Shifting Landscape}

Although historically drug marketing has been targeted to physicians, recently, as reported by the Wall Street fournal, reallocation of marketing expenditures toward nonphysician/nondetailing channels has occurred. $^{14,15}$ This includes a reduction of $>33,000$ drug-detailing sales representative jobs, a greater focus on influencing health care payers, and increasing use of "medical scientific liaisons" (MSLs).

MSLs differ from traditional drug-detailing sales representatives in that they are medical professionals themselves (eg, pharmacists, physicians, $\mathrm{PhDs}$, nurses) who interact and detail to a wide variety of health care professionals. ${ }^{16}$ They primarily provide high-level promotion of medical infor- mation about industry products to physicians, key opinion leaders, academic institutions, payers, patient associations, and other key stakeholders. ${ }^{14-16}$ Health care economic departments, which often directly interface or house these MSLs within the industry, are now taking an active role in marketing to payers because payers increasingly are emerging as gatekeepers in prescription drug use, not physicians.

This shift in industry pharmaceutical promotion also notably includes the rapid rise in the use of direct-to-consumer advertising (DTCA). ${ }^{17}$ This form of marketing, which seeks to influence consumer-patients directly and induce a demand for prescription drugs, is the fastest-growing form of drug marketing; it experienced an increase in expenditures of $330 \%$ from 1996 to 2005 and has been associated with drugs of questionable safety profiles. $^{2,18,19}$ DTCA is global in scope via the Internet, is cost effective compared with physician detailing, and has been expanded to high-traffic social media. ${ }^{17,19}$ With this transition in marketing focus and the resulting changing dynamic of the physician-patient relationship, industry marketing to physicians is becoming more irrelevant.

Collectively, these macro trends away from marketing to physicians toward other channels potentially undermine the stated goals and effect of the ACA's Sunshine provisions. The act's primary goals of increasing the transparency of industryphysician interactions and discouraging inappropriate COIs may instead be supplanted by other forms of undue influence directly to patients, payers, and other health care providers using emerging marketing strategies. Although the recent US Supreme Court ruling to uphold the majority of the ACA largely ensured the implementation of the recently published final rule, changing trends may result in an antiquated set of regulations that do not reflect the current and shifting reality of industry marketing practices and may be ineffective in efforts to contain costs.

Indeed, as patients become the focus of industry marketing efforts, the COI incentive structures change. In this regard, physicians may have less incentive to prescribe medications that previously were marketed with a physician focus. Yet physicians may respond to patient pressures for requested medications. ${ }^{20}$ With less clinical and efficacy knowledge/ information, patients may be especially susceptible to marketing claims. Consequentially, pressures on phy- 
sicians to prescribe heavily marketed drugs may shift from being based on physician COI-based pharmaceutical marketing to the increasing amount of patient requests for drugs-requests arising from DTCA. With physicians being ranked by patient satisfaction, experience, and other scores, including public (eg, Medicare) and private databases as well as inclusion in potential health plans, accountable care organizations, and other managed care, physicians may continue to face challenges associated with the influence of drug marketing. ${ }^{21}$

\section{Reform}

Actively revisiting the ACA's Sunshine provisions on a periodic basis may provide opportunities for necessary adaptation to current industry trends. CMS should proactively evaluate whether the current statute permits it to expand to additional reporting categories that could generate COIs and that are within the congressional intent of the act. These could include (1) disclosure of payments/ incentives to other nonphysician health care providers, administrators, and other health care service providers (eg, medical education and communication companies that are exempt when receiving indirect payments); (2) disclosure of exempted categories such as drug samples for therapeutic classes when a generic equivalent is available; (3) disclosure of direct-to-patient forms of rebates and incentives (such as prescription drug coupons); and (4) mandatory disclosure of other forms of influential marketing, including industry DTCA spending. If such expansion is beyond the scope of CMS' authority, it or other governmental bodies, such as the Office of the Inspector General (upon request from a member of Congress), should objectively examine what additional reporting categories might be necessary given current market conditions and trends and make recommendations to Congress for appropriate amendment of the Sunshine provisions, which could be phased in and implemented over time.

In addition, proactive measures to better curb or counter improper industry marketing practices beyond transparency efforts should also be examined critically in tandem, including (1) implementing strict bans or limits on noneducational forms of marketing (eg, meals, gifts, entertainment); and (2) funding academic detailing initiatives that provide evidence-based information to clinicians to "counter-detail” against industry-sponsored claims. Aca- demic detailing programs, which use trained health care professionals who promote evidence-based medicine free of commercial interests, have been associated with positive changes in physician education about drug use and have been used successfully by certain states and in other countries such as Canada and Australia. ${ }^{5}$ This differs from academic participation in speaking and consulting boards; in general, academic detailing programs require COI disclosures for participation, are not funded by industry, and involve detailing by uninterested parties.

Given constitutional possible limitations to banning commercial free speech and restricting pharmaceutical detailing, efforts at transparency could be supplemented by implementing professional licensure and accreditation standards for industry representatives who engage in promotion, including specifically pharmaceutical sales representatives and MSLs. Similar efforts have been attempted in the District of Columbia, which is sought to license pharmaceutical sales representatives individually, imposes penalties on licensed representatives for misleading marketing, requires adherence to certain minimum requirements, and implements fees. ${ }^{22}$ Fees from such accreditation/registration programs could then act as a funding mechanism for state-based academic detailing programs while concomitantly discouraging the presence of industry-initiated marketing.

These efforts could be championed by progressive state governments supplementing and enhancing the ACA; the Sunshine provisions specifically allow for states to implement additional transparency requirements provided they do not overlap with specific data required to be collected under the act. Hence, limited federal preemption of the act and carefully crafted state legislation would allow states flexibility that could be extended to efforts already in place in states such as California and Massachusetts and support other pending legislation advocating for gift bans, academic detailing, and sales representative registration. ${ }^{22}$

Taking this proactive stance could provide states with methods to recoup health care costs lost to overuse of prescription drugs and focus industry marketing efforts on evidence-based practices while also adapting to the changing realities of drug marketing globally. In particular, an emphasis should be placed on proactively examining new forms of 
industry promotion that are emerging quickly, such as the use of social media.

\section{Conclusion}

With the expansion of health care insurance coverage through the ACA, prescription drug expenditures are likely to continue to increase. Yet one of the primary goals of the ACA is containing the costs of prescription drugs and more efficient delivery of health care. ${ }^{11}$ The ACA's Sunshine provisions aim to meet these goals by shedding light on physician-industry relationships and hopefully influencing prescribing and purchasing behavior through discouraging COIs. However, a changing landscape shifting industry-marketing dollars away from physicians and increasingly directing them toward payers and patients could blunt the potential beneficial effect. Federal and state policy makers should proactively reassess industry marketing and transparency and redirect their focus on regulating industry marketing practices so they are consistent with cost efficiency, medical ethics, and patient safety purposes.

\section{References}

1. Gagnon M-A, Lexchin J. The cost of pushing pills: a new estimate of pharmaceutical promotion expenditures in the United States. PLoS Med 2008;5(1):e1.

2. Donohue JM, Cevasco M, Rosenthal MB. A decade of direct-to-consumer advertising of prescription drugs. N Engl J Med 2007;357:673-81.

3. Kaiser Family Foundations. Prescription drug trends. Available from http://www.kff.org/rxdrugs/upload/ 3057-08.pdf. Accessed March 10, 2012.

4. Brennan TA, Rothman DJ, Blank L, et al. Health industry practices that create conflicts of interest: a policy proposal for academic medical centers. JAMA 2006;295:429-33.

5. Liang BA, Mackey T. Confronting conflict: addressing institutional conflicts of interest in academic medical centers. Am J Law Med 2010;36:136-87.

6. Wazana A. Physicians and the pharmaceutical industry: is a gift ever just a gift? JAMA 2000;283:373-80.

7. Pew Prescription Project. Fact sheet: regulating industry payments to physicians: identifying \& minimizing conflicts of interest. Revised September 12, 2008. Available from http://www.pewhealth.org/uploadedFiles/PHG/ Supporting_Items/IB_FS_PPP_Regulating_Industry_Payments.pdf. Accessed March 10, 2012.
8. Pew Prescription Project. Fact sheet: physician payments sunshine provision in health care reform. Available from http://www.pewhealth.org/ uploadedFiles/PHG/Supporting_Items/IB_FS_PPP_ Sunshine-fact-sheet.pdf. Accessed March 10, 2012.

9. Ross JS, Lackner JE, Lurie P, Gross CP, Wolfe S, Krumholz HM. Pharmaceutical company payments to physicians: early experiences with disclosure laws in Vermont and Minnesota. JAMA 2007;297:1216-23.

10. Mackey TK, Liang BA. Transparency in physicianindustry relationships. Pathol Case Rev 2012;17: $144-7$.

11. Orszag PR, Emanuel EJ. Health care reform and cost control. N Engl J Med 2010;363:601-3.

12. Centers for Medicare \& Medicaid Services (CMS), HHS. Medicare, Medicaid, Children's Health Insurance Programs; transparency reports and reporting of physician ownership or investment interests. Final rule. Fed Regist 2013;78:9457-528.

13. Reuters. U.S. HHS says to further delay Sunshine Act rules. November 1, 2011. Available from http:// www.reuters.com/article/2011/11/01/us-sunshineact-rules-idUSTRE7A046L20111101. Accessed March 10, 2012.

14. Wang SS. Drug firms' medical staffs say what salespeople can't. June 26, 2009. Available from http:// online.wsj.com/article_email/SB124597622797657621IMyQjAxMDI5NDI1NjkyNzY2Wj.html. Accessed March 10, 2012.

15. Rockoff JD. Drug reps soften their sales pitches. January 10, 2012. Available from http://online.wsj.com/article/ SB10001424052970204331304577142763014776148. html. Accessed March 11, 2012.

16. Sass C, Albert E. The medical science liaison: an A to $Z$ guide. 2nd ed. Sudbury, MA: eBookIt.com; 2012.

17. Liang BA, Mackey T. Direct-to-consumer advertising with interactive internet media: global regulation and public health issues. JAMA 2011;305:824-5.

18. Liang BA, Mackey T. Reforming direct-to-consumer advertising. Nat Biotechnol 2011;29:397-400.

19. Liang BA, Mackey TK. Prevalence and global health implications of social media in direct-to-consumer drug advertising. J Med Internet Res 2011;13:e64.

20. Kravitz RL, Epstein RM, Feldman MD, et al. Influence of patients' requests for direct-to-consumer advertised antidepressants: a randomized controlled trial. JAMA 2005;293:1995-2002.

21. Liang BA, Mackey T. Quality and safety in medical care: what does the future hold? Arch Pathol Lab Med 2011;135:1425-31.

22. American Medical Student Association. AMSA pharmfree: state \& federal policy. Available from http:// www.pharmfree.org/policy?id=0003\#HI4. Accessed December 3, 2012. 